\title{
Are Psychological Distress and Resilience Associated with Dietary Intake Among Australian University Students?
}

\author{
Megan C. Whatnall 1,2 ${ }^{1}$, Amanda J. Patterson ${ }^{1,2}{ }^{D}$, Yu Yao Siew ${ }^{1,2}$, Frances Kay-Lambkin ${ }^{3}$ and \\ Melinda J. Hutchesson 1,2,*(D) \\ 1 School of Health Sciences, Faculty of Health and Medicine, University of Newcastle, \\ Callaghan, NSW 2308, Australia; megan.whatnall@uon.edu.au (M.C.W.); \\ amanda.patterson@newcastle.edu.au (A.J.P.); YuYao.Siew@uon.edu.au (Y.Y.S.) \\ 2 Priority Research Centre for Physical Activity and Nutrition, University of Newcastle, \\ Callaghan, NSW 2308, Australia \\ 3 Priority Research Centre for Brain and Mental Health, University of Newcastle, \\ Callaghan, NSW 2308, Australia; frances.kaylambkin@newcastle.edu.au \\ * Correspondence: melinda.hutchesson@newcastle.edu.au; Tel.: +61-249-215-405
}

Received: 13 September 2019; Accepted: 22 October 2019; Published: 24 October 2019

check for updates

\begin{abstract}
University students report unhealthy diets and experience poorer mental health than the general population. This study explores the association between psychological distress and resilience with dietary intake in a sample of Australian university students. Cross-sectional data from the University of Newcastle Student Healthy Lifestyle Survey 2017 were analysed. Psychological distress (Kessler Scale), resilience (Brief Resilience Scale) and fruit, vegetable, soft drink, takeaway food and breakfast intakes (short diet questions) were assessed. Socio-demographic (e.g., gender), student (e.g., undergraduate/postgraduate) and health characteristics (e.g., physical activity) were captured. Multivariate linear regression models explored associations between psychological distress and resilience with dietary intake, with adjustment for potential confounders. Analysis included 2710 students (mean age $26.9 \pm 9.5$ years, 30.4\% male). In adjusted models, lower psychological distress was associated with higher fruit $(\beta=-0.37, p=0.001)$ and vegetable $(\beta=-0.37, p<0.001)$ serves/day, more frequent breakfast consumption $(p<0.001)$ and less frequent soft drink and takeaway food consumption $(p<0.001)$. Higher resilience was associated with higher fruit $(\beta=0.03, p=0.022)$ and vegetable $(\beta=0.06, p<0.001)$ serves/day, more frequent breakfast consumption $(p=0.005)$, and less frequent soft drink $(p<0.001)$ and takeaway food consumption $(p=0.001)$. These results highlight a potential link between psychological distress and resilience with diet, and that further research in this area is warranted.
\end{abstract}

Keywords: psychological distress; resilience; dietary intake; diet; university students; college students; mental health

\section{Introduction}

University students' mental health is a growing area of concern, with some evidence indicating a higher prevalence of mental health disorders among university students than in same-aged peers not at university and the general adult population [1,2]. The World Mental Health International College Student project estimated $20-31 \%$ of university students are affected by one or more mental health disorders in any given year [3,4]. Rates of other indicators of mental health, such as stress and psychological distress, are also high [2,5]. For instance, among 26,000 students in the Fall 2018 American College Health Assessment survey, 45\% reported experiencing more than average stress 
in the previous year, and $13 \%$ reported experiencing tremendous stress [5]. In an Australian study comparing psychological distress among university students and national data from age-matched non-studying peers, the rate of very high psychological distress was 19\% among students and 3\% among their non-studying peers [1].

The high psychological distress rates among university students may stem from concern around academic factors (study time management and academic performance), as well as environmental factors (managing finances, juggling study with work, family, social and other commitments, changes in living arrangements and managing new social relationships) [2]. The combination of these academic and environmental factors may particularly contribute to the discrepancies in psychological distress observed between studying and non-studying peers [2,6]. For example, Ibrahim et al. suggested university students may experience more stresses in relation to future employment or dissatisfaction with their studies, and that being a student may predispose an individual to depression, due to associated factors such as leaving the family home and a lack of family support [6].

Psychological distress among university students may also be associated with resilience; a measure of the ability to recover from stress [7]. Cross-sectional studies have identified that a low level of resilience pre-dates and predisposes university students to psychological distress [8-11], consistent with a theoretical model of resilience, coping or regulatory strategies and academic performance posited by Johnson et al. [10]. The model proposes that higher resilience leads to greater use of adaptive regulatory strategies in the face of stress (including time management, effort regulation and self-regulation, including healthy behaviors), which then influences higher academic achievement [10]. On the flipside, low resilience is indirectly associated with lower academic achievement, mediated by a lack of adaptive coping strategies and higher psychological distress. Higher psychological distress among university students has also been associated with unhealthy lifestyle behaviours, including unhealthy diet, excessive consumption of alcohol and smoking [12-14].

In the general adult population, observational studies consistently demonstrate that consuming an unhealthy diet is associated with a higher likelihood of mental health problems [15]. Lower intakes of nutrient rich foods, such as fruit and vegetables, and higher intakes of energy-dense nutrient poor foods, are independently associated with higher rates of depression, and higher psychological distress and stress [15-20]. Among university students, approximately 45 studies have been conducted to date which explore associations between mental health and diet. These are predominantly cross-sectional analyses from western countries, and have explored associations between diet with depression, anxiety and/or stress. Overall, these studies support that an unhealthy diet is associated with poorer mental health. For example, studies from Canada, France and the UK, found low fruit and vegetable intakes, higher intakes of added sugars, sweets and fast food, as well as irregular meal patterns were associated with higher odds of depression, anxiety and stress [21-23].

Most studies exploring diet and mental health are in general adult populations or older adults, and of these, some indicate that the relationship between diet and mental health is moderated by other health behaviours or socio-demographic characteristics, for example physical activity, smoking, body mass index and age $[15,24,25]$. Further, results from general populations may not be applicable to university students as they are a unique population group, due to elements of their environment (personal and social) that are specifically relevant to the life-stage and the setting [26]. Of the studies among university students, only one has explored the association between diet and psychological distress [27] and none have explored diet and resilience. These are therefore significant gaps in the evidence, and worthy of further investigation given the high rates of both psychological distress and unhealthy diets among university students $[1,5,28-30]$, as well as the proposed link between psychological distress and resilience [8-11]. Further, only two studies have been conducted in Australian university students exploring diet and mental health [31,32]. Papier et al. demonstrated dose-response trends between higher stress levels with higher consumption of unhealthy foods, such as processed foods and alcohol, and lower consumption of healthy foods, such as fruit and vegetables [31]. While Di Benedetto et al., in a cluster analysis of health behaviours and mental health risk, found that higher severity of 
depression, anxiety, and/or stress and not meeting guidelines for fruit intake clustered together [32]. However, neither of these two studies assessed psychological distress or resilience. Results from studies conducted in different countries, such as Canada, France and the UK may not be applicable to Australia due to differences in culture and dietary recommendations. The aim of this cross-sectional analysis was to explore the associations between psychological distress and resilience with dietary intake in a sample of Australian university students.

\section{Materials and Methods}

\subsection{Study Design}

This study was a secondary analysis of data from an online cross-sectional survey, the 2017 University of Newcastle (UON) Student Healthy Lifestyle Survey (SHLS). The full survey methods and results have been published elsewhere [33]. The aim of the SHLS is to identify lifestyle-related health risk factors, mental health and wellbeing and overweight/obesity prevalence. Study measures were selected to achieve this primary aim. The survey was conducted via Survey Monkey (www. surveymonkey.com.au) and was open from 4 September to 1 October 2017 (during the middle of the semester for most participants). The survey tool allowed access on a single device to prevent multiple entries by the same individual. The survey included 61 questions displayed over 27 pages and took approximately 15 minutes to complete based on pilot testing. Survey questions of a sensitive nature were optional to complete, including drug use, sexual health, and mental health questions. The current analysis specifically focused on mental health and dietary intake data. The study conduct and reporting were compliant with STROBE-nut guidelines [34].

\subsection{Participants and Recruitment}

All students enrolled at the UON as of 4 September $2017(n=33,783)$ were invited to participate. Eligibility criteria included current enrolment as a student at the UON. To determine eligibility, a screening question asked individuals if they were a current student. The UON is a large urban university with students based at the main campus in Newcastle, New South Wales (NSW), Australia, additional smaller campuses across NSW $(n=4)$ and online/distance cohorts. Invitations were sent to students via an email to their UON email account on the 4th September 2017, with reminder emails sent on the 13th and 25th of September 2017. University teaching staff were emailed requesting they promote the survey in class or on the online learning management system using the recruitment materials provided by the researchers. The survey was also promoted via UON student social media accounts, digital signage across all campuses and posters at the main campus. On completing the survey, participants could choose to enter a prize draw to win one of five gift vouchers to the value of $\$ A U 100$. All participants gave informed consent prior to participating. Study approval was obtained from the UON Human Research Ethics Committee (H-2015-0459).

\subsection{Measures}

\subsubsection{Dietary Intake}

Dietary intake was assessed using short diet questions from the NSW Adult Population Health Survey [35]. This dietary assessment method was selected on this basis of the primary aim of the SHLS from which the current study data was derived for secondary analysis, i.e., an appropriate tool for monitoring and surveillance. The five dietary intake questions analysed in this study were serves per day of fruit ("Don't eat" to " $\geq 6$ serves"), where one serve was defined as 150 grams as per the Australian Guide to Healthy Eating (AGHE) [36]; serves per day of vegetables ("Don't eat" to " $\geq 6$ serves"), where one serve was defined as 75 grams [36]; consumption frequency of soft drink, cordial or sports drinks (" $\leq 1$ cup/week" to " $\geq 2$ cups/day"), with 1 cup defined as $250 \mathrm{~mL}$; takeaway meals or snacks ("Never/rarely" to "Everyday"); and breakfast ("Never/rarely" to "Everyday"). The questions assess usual 
intake, not a specific reference time period. The fruit and vegetable questions have demonstrated good relative validity and consistency compared with other dietary assessment methods; biomarkers and $24 \mathrm{~h}$ recall [37,38]. For fruit and vegetable questions compared with biomarkers, statistically significant associations were found between increasing serum carotenoid and red-cell folate mean concentrations and increasing serves per day categories [38]. The relative validity of the breakfast intake question was deemed poor compared with the $24 \mathrm{~h}$ recall method [37], where the validity of the remaining questions has not been assessed.

\subsubsection{Psychological Distress}

Psychological distress was assessed using the Kessler Psychological Distress Scale (K-10) [39]. The K-10 is a measure of non-specific psychological distress. Participants were asked to rate the frequency with which they experienced each of 10 items, for example, "About how often did you feel hopeless", over the previous month on a 5 -point Likert scale $(1=$ None of the time to $5=$ All of the time $)$. The scores for each question sum to a total score between 10-50, which corresponds to the following categories of non-specific psychological distress; low (10-15), moderate (16-21), high (22-29), or very high (30-50) risk.

\subsubsection{Resilience}

Resilience was assessed using the Brief Resilience Scale (BRS) [7]; a measure of the ability to recover from stress as an underlying psychological trait. Participants were asked to rate their level of agreement with each of six items, for example, "I tend to bounce back quickly after hard times", on a 5-point Likert scale (Strongly agree to Strongly disagree). Three of the items are negatively worded and three are positively worded, and responses are scored between $1-5$, with a higher score indicating higher resilience. The participants' average score across the items was calculated and compared with the following categories: low (1.00-2.99), normal (3.00-4.30) or high (4.31-5.00) resilience.

\subsubsection{Socio-Demographic and Student Characteristics}

Socio-demographic data collected included gender, age, country of birth, Aboriginal or Torres Strait Islander (ATSI) background, marital status, living situation and source(s) of financial support (parents/guardians, partner, government, scholarship, other or none). Student specific data collected included degree type, faculty of study and number of years studying.

\subsubsection{Health Behaviours}

Physical activity (PA) was assessed using the Active Australia Survey, including the total time (minutes) and number of sessions spent walking and performing moderate and vigorous activity in the previous week [40]. PA data were compared with national recommendations $(\geq 150$ minutes moderate activity/week over $\geq$ five sessions) to determine sufficiency [41]. Sitting time was assessed using questions from the NSW Adult Population Health Survey, including average sitting time on a weekend day and on a weekday [35]. The average total sitting time was then calculated as [(total time spent sitting on a weekday $\times 5)+($ total time spent sitting on a weekend day $\times 2) / 7]$. Smoking status was assessed and categorised into smokers (those indicating they smoke daily or occasionally) and non-smokers (all other responses) [35]. Alcohol and drug use were assessed via the Alcohol Use Disorders Identification Test (AUDIT) and Drug Use Disorders Identification Test (DUDIT), respectively [42,43]. AUDIT and DUDIT are screening tools to identify and grade alcohol and drug abuse or risk of. The cut points for the AUDIT include abstinence/low risk (0-7), moderate risk (8-15), harmful/hazardous use (16-19), or dependence (20-40). The cut points for the DUDIT are sex specific and include no drug related problems (males 0-5, females 0-1), drug related problems (males 6-24, females 2-24), or heavily dependent on drugs (25-44). Sleep was assessed via a question from the National Centre for Chronic Disease Prevention and Health Promotion, where participants reported their average hours of sleep in a 24-hr period [44]. Average hours of sleep were then compared with 
the Sleep Health Foundation age-based recommendations [44], these include 8-10 hours for 17-year olds, 7-9 hours for 18-64 year olds, and 7-8 hours for those $\geq 65$ years. Body mass index (BMI) was calculated using the standard equation (weight $(\mathrm{kg}) / \mathrm{height}\left(\mathrm{m}^{2}\right)$ ) from participants reported height in $\mathrm{cm}$ and weight in $\mathrm{kg}$, and compared with the World Health Organization BMI cut points [45].

\subsubsection{Statistical Analysis}

Analysis was conducted using STATA statistical software version 14.1. Demographic and health characteristics, dietary intake, psychological distress and resilience were described as percentages for categorical variables and means and standard deviations (SD) for continuous variables. A total of 3529 individuals responded to the survey, of which 3464 consented and were eligible to participate, and 3076 completed all compulsory questions. The total included in this analysis was 2710 . Participants were excluded from the analysis if they were missing data on psychological distress $(n=114)$, resilience $(n=30)$, drug use $(n=35)$ or BMI $(n=26)$, or due to implausible data on physical activity $(n=160)$ or sleep $(n=1)$. Differences in demographic characteristics between those included in this analysis and those who chose not to complete the psychological distress and resilience questions were also assessed, with no significant differences found. Unadjusted linear regression models were used to explore associations between psychological distress (Kessler total score) and resilience (Brief Resilience Scale total score) with sociodemographic and student characteristics, health behaviours and dietary intake (vegetable, fruit, soft drink, takeaway foods and breakfast), to identify potential confounders. Statistical significance for the identification of potential confounders was set at $p<0.2$. Fully adjusted linear regression models were used to explore associations between psychological distress and resilience with dietary intake, including the demographic and health characteristics found to be significant in the unadjusted models as potential confounders. Due to the large number of potential confounders identified and to prevent over-adjustment, backwards stepwise regression with comparison of Bayesian information criterion was used to eliminate potential confounders not contributing to the models and identify the models with best fit. Statistical significance for the fully adjusted models was set at $p<0.05$. For measures with both a continuous and a categorical variable (age, physical activity, sleep, alcohol use, drug use and BMI), the continuous variable was included in fully adjusted models.

\section{Results}

\subsection{Summary of Sample Characteristics}

Participants' mean \pm SD age was $26.9 \pm 9.5$ years (Table 1$)$. The majority $(56.4 \%)$ were aged 17-24 years, which is consistent with university students across Australia (64\% aged 17-24 years) [46]. Most participants were female (69.1\%) and born in Australia (82.0\%). Participants were undergraduate $(70.7 \%)$, postgraduate $(21.8 \%$ ) and enabling (i.e., transition to university) and English language course students $(7.5 \%)$. Most students were living in private rental accommodation off-campus $(40.6 \%)$ or their parents' home (33.2\%). Students were from all five faculties across the university, with the largest proportions from Health and Medicine (31.0\%) and Education and Arts (24.5\%) faculties. Approximately half of the participants $(51.0 \%)$ consumed 2 or more serves per day of fruit, while only $11.6 \%$ consumed 5 or more serves per day of vegetables. The majority of the participants consumed 1 cup or less per week of soft drink, cordial or sports drinks (74.0\%) and consumed takeaway foods less than one day per week (69.3\%), while just over half (58.2\%) consumed breakfast every day. 
Table 1. Mean psychological distress and resilience scores of a sample of Australian university students by demographic and health characteristics $(n=2710)$.

\begin{tabular}{|c|c|c|c|c|}
\hline Variable & $N$ or Mean & $\%$ or SD & $\begin{array}{l}\text { K10 Score }{ }^{a} \\
(\text { Mean } \pm \text { SD) }\end{array}$ & $\begin{array}{l}\text { BRS Score }^{b} \\
(\text { Mean } \pm \text { SD) }\end{array}$ \\
\hline \multicolumn{5}{|l|}{ Gender $*,+$} \\
\hline Male & 824 & 30.4 & $19.5 \pm 7.5$ & $3.5 \pm 0.8$ \\
\hline Female & 1872 & 69.1 & $21.0 \pm 7.9$ & $3.2 \pm 0.8$ \\
\hline Another gender identity & 14 & 0.5 & $25.2 \pm 7.7$ & $3.0 \pm 0.7$ \\
\hline Age (years) (Mean \pm SD) ${ }^{*, \dagger}$ & 26.9 & 9.5 & & \\
\hline$\leq 20$ years old & 688 & 25.4 & $21.9 \pm 8.1$ & $3.2 \pm 0.8$ \\
\hline $21-24$ years & 841 & 31.0 & $21.4 \pm 7.7$ & $3.2 \pm 0.8$ \\
\hline 25-29 years & 475 & 17.5 & $21.2 \pm 8.2$ & $3.3 \pm 0.8$ \\
\hline 30-39 years & 398 & 14.7 & $18.7 \pm 7.0$ & $3.4 \pm 0.8$ \\
\hline$\geq 40$ years & 308 & 11.4 & $16.9 \pm 6.2$ & $3.6 \pm 0.8$ \\
\hline \multicolumn{5}{|l|}{ Country of birth ${ }^{c, *, t}$} \\
\hline Australia & 2215 & 82.0 & $21.0 \pm 7.9$ & $3.3 \pm 0.8$ \\
\hline Other & 486 & 18.0 & $18.6 \pm 7.3$ & $3.4 \pm 0.8$ \\
\hline \multicolumn{5}{|l|}{ Aboriginal or Torres Strait Islander background $*,+$} \\
\hline Yes & 75 & 2.8 & $24.1 \pm 9.6$ & $3.0 \pm 1.0$ \\
\hline No & 2635 & 97.2 & $20.5 \pm 7.7$ & $3.3 \pm 0.8$ \\
\hline \multicolumn{5}{|l|}{ Marital Status *,t } \\
\hline Never married & 1858 & 68.6 & $21.4 \pm 8.0$ & $3.2 \pm 0.8$ \\
\hline Married & 458 & 16.9 & $17.3 \pm 6.0$ & $3.5 \pm 0.8$ \\
\hline Defacto & 287 & 10.6 & $20.6 \pm 7.6$ & $3.0 \pm 0.9$ \\
\hline Separated & 35 & 1.3 & $21.2 \pm 9.8$ & $3.5 \pm 0.9$ \\
\hline Divorced & 67 & 2.5 & $20.2 \pm 8.9$ & $3.5 \pm 0.8$ \\
\hline Widowed & 5 & 0.2 & $13.6 \pm 3.4$ & $4.3 \pm 0.6$ \\
\hline \multicolumn{5}{|l|}{ Living Situation $*,+$} \\
\hline Own home & 410 & 15.1 & $17.4 \pm 6.1$ & $3.6 \pm 0.8$ \\
\hline Parents home & 900 & 33.2 & $21.6 \pm 7.7$ & $3.2 \pm 0.8$ \\
\hline On-campus & 223 & 8.2 & $20.8 \pm 7.7$ & $3.3 \pm 0.8$ \\
\hline Renting & 1099 & 40.6 & $20.7 \pm 8.0$ & $3.3 \pm 0.8$ \\
\hline Boarding/Homestay & 53 & 2.0 & $23.5 \pm 9.3$ & $3.1 \pm 0.9$ \\
\hline Irregular & 25 & 0.9 & $25.1 \pm 9.9$ & $2.9 \pm 0.9$ \\
\hline \multicolumn{5}{|l|}{ Receiving financial support $*,+$} \\
\hline Yes & 1700 & 62.7 & $21.1 \pm 7.9$ & $3.2 \pm 0.8$ \\
\hline No & 1010 & 37.3 & $19.7 \pm 7.6$ & $3.4 \pm 0.8$ \\
\hline \multicolumn{5}{|l|}{ Type of degree $*, t$} \\
\hline Undergraduate & 1917 & 70.7 & $21.2 \pm 7.9$ & $3.3 \pm 0.8$ \\
\hline Postgraduate & 591 & 21.8 & $17.9 \pm 6.5$ & $3.5 \pm 0.8$ \\
\hline Other $^{\mathrm{d}}$ & 202 & 7.5 & $22.2 \pm 9.0$ & $3.2 \pm 0.8$ \\
\hline \multicolumn{5}{|l|}{ Faculty of Study $*,+$} \\
\hline Business and Law & 363 & 13.4 & $20.1 \pm 7.7$ & $3.4 \pm 0.8$ \\
\hline Education and Arts & 663 & 24.5 & $21.8 \pm 8.4$ & $3.2 \pm 0.8$ \\
\hline Engineering & 327 & 12.1 & $20.3 \pm 7.4$ & $3.4 \pm 0.8$ \\
\hline Health and Medicine & 839 & 31.0 & $19.3 \pm 7.1$ & $3.4 \pm 0.8$ \\
\hline Science & 370 & 13.7 & $21.2 \pm 7.8$ & $3.3 \pm 0.8$ \\
\hline English Language and Foundation Studies & 148 & 5.5 & $22.8 \pm 9.1$ & $3.1 \pm 0.8$ \\
\hline \multicolumn{5}{|l|}{ Number of years studying } \\
\hline 1st year & 1055 & 38.9 & $21.0 \pm 8.0$ & $3.3 \pm 0.8$ \\
\hline 2nd year & 553 & 20.4 & $20.5 \pm 8.0$ & $3.3 \pm 0.9$ \\
\hline 3rd year & 530 & 19.6 & $20.4 \pm 7.6$ & $3.3 \pm 0.8$ \\
\hline 4 th year & 299 & 11.0 & $20.3 \pm 7.3$ & $3.4 \pm 0.8$ \\
\hline 5th year or later & 273 & 10.1 & $20.1 \pm 7.7$ & $3.3 \pm 0.8$ \\
\hline Physical activity (mins/week) (Mean \pm SD) $*,+$ & 350 & 307 & & \\
\hline
\end{tabular}


Table 1. Cont.

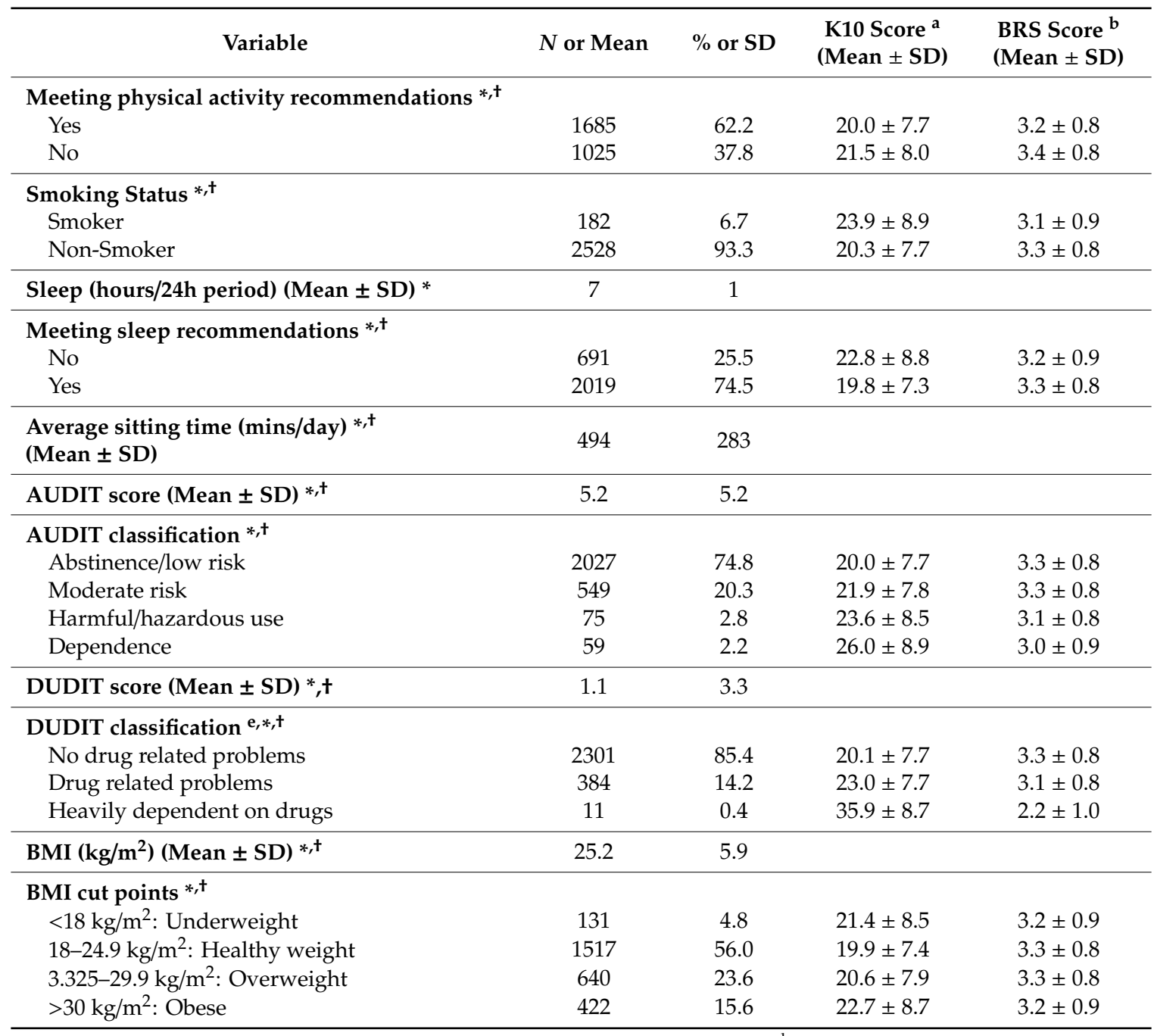

${ }^{\mathrm{a}} \mathrm{K}-10$ score range $10-50$, higher score indicates higher psychological distress. ${ }^{\mathrm{b}}$ BRS score range $1-5$, higher score indicates higher resilience. ${ }^{\mathrm{c}} n=2701$ ( $n=9$ unspecified). ${ }^{\mathrm{d}}$ Includes students enrolled in enabling (i.e., transition to university) courses and English language courses for international students. ${ }^{\mathrm{e}} n=2696$ as classifications are sex specific ( $n=14$ participants indicated other gender identity). * Indicates statistically significant difference in psychological distress at $p<0.2$ level. ${ }^{\dagger}$ Indicates statistically significant difference in resilience at $p<0.2$ level.

\subsection{Summary of Psychological Distress and Resilience}

The percentage of participants in each category of non-specific psychological distress risk was $30.8 \%$ low, $32.0 \%$ moderate, $22.9 \%$ high and $14.3 \%$ very high risk. The percentage of participants with low resilience was $29.7 \%$, with $59.9 \%$ classified as normal resilience, and $10.4 \%$ high resilience. The mean \pm SD psychological distress risk score was $20.6 \pm 7.8$ out of 50 , and the mean \pm SD resilience score was $3.3 \pm 0.8$ out of 5 . Unadjusted linear regression of psychological distress and resilience found that lower psychological distress score was significantly associated with higher resilience score $(\beta=-5.716, p<0.001)$.

\subsection{Associations between Psychological Distress and Resilience with Dietary Intake}

Results of the unadjusted models for psychological distress and resilience with dietary intake are presented in Table 2. Results of the unadjusted models for psychological distress and resilience with demographic and health characteristics (potential confounders) are presented in Table 1. Fully adjusted models for psychological distress and resilience with dietary intake are presented in Table 3, with the adjustments for potential confounders described in the footnote. Supplementary Table S1 
includes the full results of the adjusted models for psychological distress and resilience with dietary intake, i.e., including the potential confounders adjusted for.

Table 2. Mean psychological distress and resilience scores of a sample of Australian university students by dietary intake $(n=2710)$.

\begin{tabular}{|c|c|c|c|c|}
\hline Variable & $N$ & $\%$ & $\begin{array}{l}\text { K10 Score }^{a} \\
(\text { Mean } \pm \text { SD) }\end{array}$ & $\begin{array}{l}\text { BRS Score }{ }^{b} \\
(\text { Mean } \pm \text { SD) }\end{array}$ \\
\hline \multicolumn{5}{|l|}{ Vegetable (serves/day) *,t } \\
\hline 0 & 12 & 0.4 & $23.8 \pm 6.4$ & $3.2 \pm 0.8$ \\
\hline$<1$ & 195 & 7.2 & $22.5 \pm 8.7$ & $3.1 \pm 0.9$ \\
\hline 1 & 437 & 16.1 & $21.4 \pm 8.5$ & $3.2 \pm 0.8$ \\
\hline 2 & 738 & 27.2 & $20.8 \pm 7.7$ & $3.3 \pm 0.8$ \\
\hline 3 & 644 & 23.8 & $20.3 \pm 7.4$ & $3.3 \pm 0.8$ \\
\hline 4 & 369 & 13.6 & $20.0 \pm 7.4$ & $3.4 \pm 0.8$ \\
\hline 5 & 184 & 6.8 & $19.3 \pm 7.3$ & $3.4 \pm 0.8$ \\
\hline 6 or more & 131 & 4.8 & $18.4 \pm 7.6$ & $3.6 \pm 0.9$ \\
\hline \multicolumn{5}{|l|}{ Fruit (serves/day) $*,+$} \\
\hline 0 & 70 & 2.6 & $23.4 \pm 8.8$ & $3.3 \pm 1.0$ \\
\hline$<1$ & 447 & 16.5 & $22.0 \pm 8.6$ & $3.2 \pm 0.9$ \\
\hline 1 & 811 & 29.9 & $20.8 \pm 7.7$ & $3.3 \pm 0.8$ \\
\hline 2 & 828 & 30.6 & $19.9 \pm 7.4$ & $3.3 \pm 0.8$ \\
\hline 3 & 378 & 14.0 & $19.9 \pm 7.7$ & $3.4 \pm 0.8$ \\
\hline 4 & 112 & 4.1 & $19.8 \pm 7.0$ & $3.4 \pm 0.8$ \\
\hline 5 & 33 & 1.2 & $19.2 \pm 8.4$ & $3.4 \pm 0.9$ \\
\hline 6 or more & 31 & 1.1 & $20.4 \pm 9.1$ & $3.3 \pm 1.0$ \\
\hline \multicolumn{5}{|l|}{ Soft drink $*, t$} \\
\hline 1 cup or less per week & 2006 & 74.0 & $19.9 \pm 7.4$ & $3.3 \pm 0.8$ \\
\hline 2-6 cups per week & 514 & 19.0 & $22.0 \pm 8.2$ & $3.2 \pm 0.8$ \\
\hline 1 cup per day & 99 & 3.7 & $23.7 \pm 9.1$ & $3.0 \pm 0.8$ \\
\hline 2 or more cups per day & 91 & 3.4 & $24.1 \pm 9.8$ & $3.0 \pm 0.8$ \\
\hline \multicolumn{5}{|l|}{ Takeaway food $*, \dagger$} \\
\hline Less than once per week & 1879 & 69.3 & $19.7 \pm 7.5$ & $3.4 \pm 0.8$ \\
\hline 1-2 times per week & 673 & 24.8 & $22.2 \pm 8.2$ & $3.2 \pm 0.8$ \\
\hline 3-4 times per week & 132 & 4.9 & $23.2 \pm 7.9$ & $3.1 \pm 0.8$ \\
\hline 5-6 times per week & 23 & 0.9 & $25.9 \pm 10.4$ & $2.9 \pm 0.8$ \\
\hline Everyday & 3 & 0.1 & $34.7 \pm 9.5$ & $3.1 \pm 1.0$ \\
\hline \multicolumn{5}{|l|}{ Breakfast $*,+$} \\
\hline Less than once per week & 268 & 9.9 & $23.9 \pm 9.3$ & $3.1 \pm 0.8$ \\
\hline 1-2 times per week & 234 & 8.6 & $22.0 \pm 8.2$ & $3.3 \pm 0.8$ \\
\hline 3-4 times per week & 299 & 11.0 & $21.5 \pm 8.3$ & $3.2 \pm 0.8$ \\
\hline 5-6 times per week & 332 & 12.3 & $21.6 \pm 7.4$ & $3.2 \pm 0.8$ \\
\hline Everyday & 1577 & 58.2 & $19.4 \pm 7.2$ & $3.4 \pm 0.8$ \\
\hline
\end{tabular}

a $\mathrm{K}-10$ score range 10-50, higher score indicates higher psychological distress. ${ }^{\mathrm{b}}$ BRS score range 1-5, higher score indicates higher resilience. * Indicates statistically significant difference in psychological distress at $p<0.2$ level. ${ }^{+}$Indicates statistically significant difference in resilience at $p<0.2$ level.

In the adjusted models (Table 3), controlling for demographic and health characteristics, lower psychological distress score (i.e., lower risk of non-specific psychological distress) was significantly associated with higher serves per day of vegetables $(\beta=-0.368, p<0.001)$ and fruit $(\beta=-0.374$, $p=0.001)$, higher frequency of breakfast consumption $(p<0.001)$, and lower frequencies of soft drink, cordial or sports drink $(p<0.001)$ and takeaway food $(p<0.001)$ consumption.

In the adjusted models, higher resilience score (i.e., higher resilience) was significantly associated with higher serves per day of vegetables $(\beta=0.055, p<0.001)$ and fruit $(\beta=0.028, p=0.022)$, higher frequency of breakfast consumption $(p=0.005)$, and lower frequencies of soft drink, cordial or sports drink $(p<0.001)$ and takeaway food $(p=0.001)$ consumption. 
Table 3. Linear regression results of psychological distress and resilience scores with dietary intake in a sample of Australian university students $(n=2710)$.

\begin{tabular}{|c|c|c|c|c|c|c|}
\hline & \multicolumn{3}{|c|}{ Psychological Distress Score } & \multicolumn{3}{|c|}{ Resilience Score } \\
\hline & $\beta$-Coefficient ${ }^{a}$ & SE & $p$ & $\beta$-Coefficient ${ }^{a}$ & SE & $p$ \\
\hline Vegetable (serves/day) & -0.368 & 0.096 & $<0.001^{b}$ & 0.055 & 0.010 & $<0.001^{\mathrm{d}}$ \\
\hline Fruit (serves/day) & -0.374 & 0.113 & $0.001^{b}$ & 0.028 & 0.012 & $0.022^{\mathrm{e}}$ \\
\hline $\begin{array}{l}\text { Soft drink } \\
\quad \text { Reference category }=1\end{array}$ & or less per week & & $<0.001^{\mathrm{c}}$ & & & $<0.001^{\mathrm{f}}$ \\
\hline 2-6 cups per week & 1.409 & 0.360 & $<0.001$ & -0.095 & 0.039 & 0.014 \\
\hline 1 cup per day & 2.471 & 0.742 & 0.001 & -0.223 & 0.080 & 0.005 \\
\hline 2 or more cups per day & 2.387 & 0.785 & 0.002 & -0.235 & 0.084 & 0.005 \\
\hline $\begin{array}{l}\text { Takeaway food } \\
\text { Reference category }=\mathrm{Le}\end{array}$ & han once per wee & & $<0.001^{b}$ & & & $0.001^{\mathrm{e}}$ \\
\hline 1-2 times per week & 1.441 & 0.332 & $<0.001$ & -0.124 & 0.035 & $<0.001$ \\
\hline 3-4 times per week & 1.279 & 0.661 & 0.053 & -0.129 & 0.071 & 0.069 \\
\hline 5-6 times per week & 3.613 & 1.514 & 0.017 & -0.380 & 0.162 & 0.019 \\
\hline Everyday & 9.494 & 4.162 & 0.023 & 0.031 & 0.446 & 0.944 \\
\hline $\begin{array}{l}\text { Breakfast } \\
\quad \text { Reference category }=\mathrm{Le}\end{array}$ & han once per wee & & $<0.001$ & & & $0.005^{\mathrm{e}}$ \\
\hline 1-2 times per week & -1.228 & 0.637 & 0.054 & 0.137 & 0.069 & 0.046 \\
\hline 3-4 times per week & -2.078 & 0.599 & 0.001 & 0.076 & 0.064 & 0.237 \\
\hline 5-6 times per week & -1.780 & 0.588 & 0.002 & 0.002 & 0.063 & 0.978 \\
\hline Everyday & -3.004 & 0.481 & $<0.001$ & 0.142 & 0.051 & 0.006 \\
\hline
\end{tabular}

${ }^{a} \beta$-Coefficient indicates the increase in psychological distress or resilience score per unit increase in the dietary intake variable. Higher psychological distress score indicates higher psychological distress, higher resilience score indicates higher resilience. ${ }^{b}$ Models adjusted for age, gender, Aboriginal or Torres Strait Islander background, living situation, financial support, type of degree, faculty of study, physical activity time, smoking, sleep time, sitting time, AUDIT score, DUDIT score, and BMI. ${ }^{c}$ Models adjusted for age, gender, Aboriginal or Torres Strait Islander background, living situation, financial support, type of degree, faculty of study, physical activity time, sleep time, sitting time, AUDIT score, DUDIT score, and BMI. ${ }^{\mathrm{d}}$ Models adjusted for age, gender, marital status, living situation,

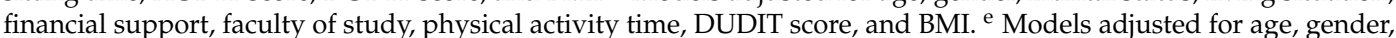
living situation, financial support, faculty of study, physical activity time, DUDIT score, and BMI. ${ }^{\mathrm{f}}$ Models adjusted for age, gender, living situation, financial support, faculty of study, physical activity time, AUDIT score, DUDIT score, and BMI. Significant $p$-values in bold.

\section{Discussion}

This cross-sectional study investigated the associations between psychological distress, resilience and dietary intake in a sample of Australian university students. Thirty-seven percent of the sample had high or very risk of psychological distress, and $30 \%$ had low resilience. Fifty percent of the sample consumed 2 or more serves per day of fruit, and $11 \%$ consumed 5 or more serves per day of vegetables. Around $70 \%$ of the sample each consumed 1 cup or less per week of soft drink and consumed takeaway foods less than one day per week. Fifty eight percent consumed breakfast every day. Associations were found between lower risk of psychological distress and higher resilience with higher intakes of vegetables and fruit, more frequent breakfast consumption, and less frequent intakes of soft drink and takeaway food.

The present study found that psychological distress scores, on a score range of 10-50, were 0.37 points lower for each additional serve/day of vegetables or fruit, and 3.00 points lower for consumption of breakfast everyday compared with less than once/week. It was also found that psychological distress scores were 2.39 points higher for consumption of two or more cups/day of soft drink compared with one cup or less/week, and 9.49 points higher for consumption of takeaway food everyday compared with less than once/week. These findings are consistent with the study by Knowlden et al. of 195 university students from the USA, which used the similar 6-item Kessler Scale to assess psychological distress [27]. Knowlden et al. found that participants with low compared with severe psychological distress risk consumed significantly higher quantities of fruit and significantly lower quantities of sugar-sweetened beverages, however, found no significant differences in psychological distress risk related to vegetable intake. There is also consistency between the current study findings with studies among university students and young adults for other mental health outcomes. That is, 
other studies have found associations between higher intakes of fruit and vegetables with lower risk of depression and stress [21,23,31], and between higher intakes of added sugars, sweets, fast food and processed foods with higher risk of depression, stress and anxiety, and lower wellbeing [21,23,31,47].

The present study also found that resilience scores, on a range of $1-5$, were 0.06 and 0.03 points higher for each additional serve/day of vegetables and fruit respectively, and 0.14 points higher for consumption of breakfast everyday compared with less than once/week. It was also found that resilience scores were 0.24 points lower for consumption of two or more cups/day of soft drink compared with one cup or less/week, and 0.38 points lower for consumption of takeaway food 5-6 times/week compared with less than once/week. As this is one of the first studies to assess resilience in relation to diet, studies to compare with are limited. However, these findings are somewhat consistent with a study of 1853 Chinese university students by Chu et al., where students who placed a greater importance on nutrition had a higher sense of coherence (a measure of an individual's sense of optimism and control) [48]. Additionally, the associations between dietary behaviours and resilience observed in the current study were the inverse of that between dietary behaviours and psychological distress, which is consistent with previous studies reporting an inverse relationship between psychological distress and resilience $[2,10]$.

There is a growing body of evidence to support the link between a healthy diet and better mental health outcomes [15,49]. Much of the evidence comes from cross-sectional studies, and some studies have found no association when controlling for potential confounding factors [15]. However, there is now more evidence emerging from cohort and intervention studies, and the overall evidence supports that a link exists [50,51]. In terms of the direction of the relationship between diet and mental health, this is a complex and likely bi-directional relationship [52]. There are indications for a healthy diet contributing to improved mental health. For example, Sarris et al. suggests that it is the reliance of the brain on the necessary nutrients to function, including immune, antioxidant defence and neurotrophic systems, that implicate diet in the pathogenesis of mental health disorders [53]. Conversely, there are indications that dietary choices are influenced by mental health status. For example, studies have shown that individuals often make less healthy dietary choices during periods of stress or to alleviate feelings of stress [52]. The relationship between diet and mental health is complex with many more factors at play and requires further investigation among a range of population groups, including university students.

The National Youth Health Foundation mental health service Headspace, is a mental health service aimed at early intervention for mental health related issues, with the most common intervention being cognitive behavioural therapy (CBT), and an average of four intervention sessions per individual $[54,55]$. Analyses of data from Australian youth (aged 12-25 years) attending Headspace calculated a Reliable Change Index (RCI) as a 7-point change in K-10 score from first to last intervention session [54,55]. The magnitude of the associations between dietary intake and K-10 scores in the present study are relatively small in comparison to the RCI, although they vary across the dietary intake measures. The findings suggest that there is a small, yet positive link between diet and psychological distress, and improving one might have a positive effect on the other.

Another interesting point of comparison is the magnitude of the association between mental health outcomes across the different dietary intake outcomes assessed. In the current study, larger estimates were found for the associations of soft drink, takeaway and breakfast with psychological distress and resilience than for fruit and vegetables. Similarly, Knowlden et al. reported a larger association between sugar-sweetened beverages and psychological distress than for fruit [27]. In contrast, El Ansari et al. found greater associations for fruit and vegetables than for sweets and fast food in relation to stress, while for depression, the findings differed for males and females [21]. As for why certain foods or dietary components may have larger association than others, this could be related to the strength of the underlying mechanisms behind the associations between diet and mental health. These are proposed to be similar to the mechanisms between diet and cognition and cardiovascular diseases [56]. Nutrients that are known to have beneficial effects on mental health include those which protect against 
oxidative stress, such as Vitamins B6, B9 and B12, due to their interactions with homocysteine, and the antioxidant vitamins A, C and E [56], as well as polyphenols and flavonoids [57,58]. Fruits and vegetables are rich sources of these, which could explain the findings of lower psychological distress and higher resilience with higher fruit and vegetable intake. Nutrients with negative effects on mental health are those with pro-inflammatory effects, including saturated fats and sugar when consumed in excess $[56,59,60]$. The findings of higher psychological distress and lower resilience with higher intakes of takeaway and soft drink are in line with this.

As with all cross-sectional surveys, the direction of the association between psychological distress, resilience and dietary intake cannot be determined from these data, nor causality. In addition, the use of short diet questions to assess dietary intake is limiting in terms of validity compared with other dietary assessment methods, such as validated food frequency questionnaire. However, this dietary assessment method was selected on the basis of the primary aim of the survey, i.e., monitoring and surveillance, and is still an appropriate method for this study. Further, a small number of dietary behaviours were assessed. It is also a limitation that body dissatisfaction and/or eating-disordered behaviour were not assessed in this study as associations have been found between these factors and dietary intake and mental health [61-63]. Therefore, if body dissatisfaction and eating-disordered behaviour were accounted for as potential confounding factors this may have attenuated the current findings. A further limitation is the measures being self-reported. However, the use of an online, anonymous platform for collecting survey data and validated tools minimize the potential bias from self-reporting. The survey was conducted at a time during semester (i.e., the middle) that is likely to be representative of most student's typical psychological distress, resilience and dietary intake during the university year. Periods of higher academic pressure, such as exam periods were avoided. Further, the sample was a small proportion of the total UON student body (8.0\%). In terms of representativeness, the sample consisted of slightly higher proportions of female, undergraduate and domestic students compared with the average across Australian universities, however sample characteristics were otherwise consistent [46]. The representation of ATSI students was higher, however proportional to UON numbers [64]. The representativeness of the sample in terms of dietary intake, psychological distress and resilience is not able to be determined as this data does not exist for all UON students or all Australian university students. Compared with other studies among university students and with data from Australian young adults, this study sample were consuming soft drinks and takeaway foods less frequently, and a greater proportion were meeting guidelines for fruit and vegetable intake [32,65-67]. The proportion with high or very high psychological distress in the current study was similar to an earlier study among Australian university students [1]. As such, the study sample appears to be healthier than university students more generally in terms of dietary intake, and this should be considered in terms of representativeness and generalisability. Despite these limitations, the present analysis is important as it suggests that an association exists in this population group, and that further enquiry of this association is warranted. The main strengths of the present study include the use of validated tools to measure psychological distress and resilience [7,39], the large number of potential confounders accounted for in analyses, and the large sample size.

\section{Conclusions}

This cross-sectional analysis highlights a potential link between psychological distress and resilience with diet, however further research is needed to substantiate the findings. Future studies should include cohort studies to track changes in mental health and diet and their interrelationships prospectively. Further studies should also conduct more comprehensive evaluation of diet and using validated dietary assessment tools. In addition, it would be worthwhile to study the associations between diet and mental health in university students compared with matched non-studying peers. Longer term, the data collected from this and future studies of psychological distress, resilience and diet could be useful to inform mental health and/or dietary interventions to support university students. 
Supplementary Materials: The following are available online at http://www.mdpi.com/1660-4601/16/21/4099/s1, Table S1: Linear regression results of psychological distress and resilience scores with dietary intake in a sample of Australian university students $(n=2710)$, including full results of confounder variables.

Author Contributions: Conceptualization, M.J.H. and A.J.P.; methodology, M.J.H., A.J.P., Y.Y.S. and M.C.W.; data curation, Y.Y.S., M.C.W.; formal analysis, Y.Y.S. and M.C.W.; Writing-Original Draft Preparation, Y.Y.S. and M.C.W.; Writing—Review \& Editing, M.C.W., M.J.H., A.J.P., and F.K.-L.

Funding: This research received no external funding. M.H. is supported by a University of Newcastle Gladys M Brawn Career Development Fellowship (Teaching Assistance). F.K.-L. is supported by a NHMRC Senior Research Fellowship and University of Newcastle Gladys M Brawn Senior Research Fellowship.

Acknowledgments: The authors acknowledge the members of the UON Health Promotion Working Group for their contribution to the Student Healthy Lifestyle Survey.

Conflicts of Interest: The authors declare no conflict of interest.

\section{References}

1. Stallman, H.M. Psychological distress in university students: A comparison with general population data. Aust. Psychol. 2010, 45, 249-257. [CrossRef]

2. Sharp, J.; Theiler, S. A review of psychological distress among university students: Pervasiveness, implications and potential points of intervention. Int. J. Adv. Couns 2018, 40, 193-212. [CrossRef]

3. Auerbach, R.P.; Alonso, J.; Axinn, W.G.; Cuijpers, P.; Ebert, D.D.; Green, J.G.; Hwang, I.; Kessler, R.C.; Liu, H.; Mortier, P.; et al. Mental disorders among college students in the world health organization world mental health surveys-Corrigendum. Psychol. Med. 2017, 47, 2737. [CrossRef] [PubMed]

4. Auerbach, R.P.; Mortier, P.; Bruffaerts, R.; Alonso, J.; Benjet, C.; Cuijpers, P.; Demyttenaere, K.; Ebert, D.D.; Green, J.G.; Hasking, P.; et al. Who world mental health surveys international college student project: Prevalence and distribution of mental disorders. J. Abnorm. Psychol. 2018, 127, 623-638. [CrossRef] [PubMed]

5. American College Health Association. National College Health Hssessment II: Reference Group Executive Summary Fall 2018; American College Health Association: Silver Spring, MD, USA, 2018.

6. Ibrahim, A.K.; Kelly, S.J.; Adams, C.E.; Glazebrook, C. A systematic review of studies of depression prevalence in university students. J. Psychiatr. Res. 2013, 47, 391-400. [CrossRef] [PubMed]

7. Smith, B.W.; Dalen, J.; Wiggins, K.; Tooley, E.; Christopher, P.; Bernard, J. The brief resilience scale: Assessing the ability to bounce back. Int. J. Behav. Med. 2008, 15, 194-200. [CrossRef] [PubMed]

8. Sarrionandia, A.; Ramos-Diaz, E.; Fernandez-Lasarte, O. Resilience as a mediator of emotional intelligence and perceived stress: A cross-country study. Front. Psychol. 2018, 9, 2653. [CrossRef]

9. Zhang, M.; Zhang, J.; Zhang, F.; Zhang, L.; Feng, D. Prevalence of psychological distress and the effects of resilience and perceived social support among chinese college students: Does gender make a difference? Psychiatry Res. 2018, 267, 409-413. [CrossRef]

10. Johnson, M.L.; Taasoobshirazi, G.; Kestler, J.L.; Cordova, J.R. Models and messengers of resilience: A theoretical model of college students' resilience, regulatory strategy use, and academic achievement. Educ. Psychol. 2015, 35, 869-885. [CrossRef]

11. Bore, M.; Pittolo, C.; Kirby, D.; Dluzewska, T.; Marlin, S. Predictors of psychological distress and well-being in a sample of australian undergraduate students. High Educ. Res. Dev 2016, 35, 869-880. [CrossRef]

12. Kwan, M.Y.; Arbour-Nicitopoulos, K.P.; Duku, E.; Faulkner, G. Patterns of multiple health risk-behaviours in university students and their association with mental health: Application of latent class analysis. Health Promot Chronic Dis. Prev. Can. 2016, 36, 163-170. [CrossRef] [PubMed]

13. Velten, J.; Bieda, A.; Scholten, S.; Wannemuller, A.; Margraf, J. Lifestyle choices and mental health: A longitudinal survey with german and chinese students. BMC Public Health 2018, 18, 632. [CrossRef] [PubMed]

14. Pelletier, J.E.; Lytle, L.A.; Laska, M.N. Stress, health risk behaviors, and weight status among community college students. Health Educ. Behav. 2016, 43, 139-144. [CrossRef] [PubMed]

15. Jacka, F.N. Nutritional psychiatry: Where to next? EBioMedicine 2017, 17, 24-29. [CrossRef] [PubMed]

16. Li, Y.; Lv, M.R.; Wei, Y.J.; Sun, L.; Zhang, J.X.; Zhang, H.G.; Li, B. Dietary patterns and depression risk: A meta-analysis. Psychiatry Res. 2017, 253, 373-382. [CrossRef] [PubMed] 
17. Sarris, J.; Logan, A.C.; Akbaraly, T.N.; Paul Amminger, G.; Balanzá-Martínez, V.; Freeman, M.P.; Hibbeln, J.; Matsuoka, Y.; Mischoulon, D.; Mizoue, T.; et al. International society for nutritional psychiatry research consensus position statement: Nutritional medicine in modern psychiatry. World Psychiatry 2015, 14, 370-371. [CrossRef]

18. Banta, J.E.; Segovia-Siapco, G.; Crocker, C.B.; Montoya, D.; Alhusseini, N. Mental health status and dietary intake among california adults: A population-based survey. Int. J. Food Sci. Nutr. 2019, 70, 759-770. [CrossRef]

19. Taylor, A.M.; Thompson, S.V.; Edwards, C.G.; Musaad, S.M.A.; Khan, N.A.; Holscher, H.D. Associations among diet, the gastrointestinal microbiota, and negative emotional states in adults. Nutr. Neurosci 2019. [CrossRef]

20. Quehl, R.; Haines, J.; Lewis, S.P.; Buchholz, A.C. Food and mood: Diet quality is inversely associated with depressive symptoms in female university students. Can J. Diet Pract. Res. 2017, 78, 124-128. [CrossRef]

21. El Ansari, W.; Adetunji, H.; Oskrochi, R. Food and mental health: Relationship between food and perceived stress and depressive symptoms among university students in the united kingdom. Cent Eur. J. Public Health 2014, 22, 90-97. [CrossRef]

22. Tran, A.; Tran, L.; Geghre, N.; Darmon, D.; Rampal, M.; Brandone, D.; Gozzo, J.M.; Haas, H.; Rebouillat-Savy, K.; Caci, H.; et al. Health assessment of french university students and risk factors associated with mental health disorders. PLOS ONE 2017, 12, e0188187. [CrossRef] [PubMed]

23. Wattick, R.A.; Hagedorn, R.L.; Olfert, M.D. Relationship between diet and mental health in a young adult appalachian college population. Nutrients 2018, 10, 25. [CrossRef] [PubMed]

24. Chocano-Bedoya, P.O.; Fung, T.T.; Okereke, O.I.; Lucas, M.; Hu, F.B.; Mirzaei, F.; O’Reilly, E.J.; Ascherio, A. Prospective study on long-term dietary patterns and incident depression in middle-aged and older women. Am. J. Clin Nutr. 2013, 98, 813-820. [CrossRef] [PubMed]

25. Jacka, F.N.; Cherbuin, N.; Anstey, K.J.; Butterworth, P. Dietary patterns and depressive symptoms over time: Examining the relationships with socioeconomic position, health behaviours and cardiovascular risk. PLOS ONE 2014, 9, e87657. [CrossRef] [PubMed]

26. Munt, A.E.; Partridge, S.R.; Allman-Farinelli, M. The barriers and enablers of healthy eating among young adults: A missing piece of the obesity puzzle: A scoping review. Obes Rev. 2017, 18, 1-17. [CrossRef]

27. Knowlden, A.P.; Hackman, C.L.; Sharma, M. Lifestyle and mental health correlates of psychological distress in college students. Health Educ. J. 2015, 75, 370-382. [CrossRef]

28. Peltzer, K.; Pengpid, S. Correlates of healthy fruit and vegetable diet in students in low, middle and high income countries. Int. J. Public Health 2015, 60, 79-90. [CrossRef]

29. El Ansari, W.; Stock, C.; John, J.; Deeny, P.; Phillips, C.; Snelgrove, S.; Adetunji, H.; Hu, X.; Parke, S.; Stoate, M. Health promoting behaviours and lifestyle characteristics of students at seven universities in the uk. Cent Eur. J. Public Health 2011, 19, 197. [CrossRef]

30. El Ansari, W.; Stock, C.; Mikolajczyk, R.T. Relationships between food consumption and living arrangements among university students in four european countries-A cross-sectional study. Nutr. J. 2012, 11, 28. [CrossRef]

31. Papier, K.; Ahmed, F.; Lee, P.; Wiseman, J. Stress and dietary behaviour among first-year university students in australia: Sex differences. Nutrition 2015, 31, 324-330. [CrossRef]

32. Di Benedetto, M.; Towt, C.J.; Jackson, M.L. A cluster analysis of sleep quality, self-care behaviors, and mental health risk in australian university students. Behavioral Sleep Medicine 2019. [CrossRef] [PubMed]

33. Whatnall, M.; Patterson, A.; Brookman, S.; Convery, P.; Swan, C.; Pease, S.; Hutchesson, M. Lifestyle behaviors and related health risk factors in a sample of australian university students. J. Am. Coll. Health 2019, 52. [CrossRef] [PubMed]

34. Lachat, C.; Hawwash, D.; Ocke, M.C.; Berg, C.; Forsum, E.; Hornell, A.; Larsson, C.; Sonestedt, E.; Wirfalt, E.; Akesson, A.; et al. Strengthening the reporting of observational studies in epidemiology-nutritional epidemiology (strobe-nut): An extension of the strobe statement. PLoS Med. 2016, 13, e1002036. [CrossRef] [PubMed]

35. Centre for Epidemiology and Evidence. Nsw Population Health Survey 2014; NSW Ministry of Health: Sydney, Australia, 2014.

36. National Health and Medical Research Council. In Eat for Health Educator Guide; National Health and Medical Research Council: Canberra, Australia, 2013. 
37. Rutishauser, I.; Webb, K.; Abraham, B.; Allsopp, R. Evaluation of Short Dietary Questions from the 1995 National Nutrition Survey; Australian Food and Nutrition Monitoring Unit: Canberra, Australia, 2001.

38. Coyne, T.; Ibiebele, T.I.; McNaughton, S.; Rutishauser, I.H.; O’Dea, K.; Hodge, A.M.; McClintock, C.; Findlay, M.G.; Lee, A. Evaluation of brief dietary questions to estimate vegetable and fruit consumption-Using serum carotenoids and red-cell folate. Public Health Nutr. 2005, 8, 298-308. [CrossRef]

39. Kessler, R.C.; Andrews, G.; Colpe, L.J.; Hiripi, E.; Mroczek, D.K.; Normand, S.L.; Walters, E.E.; Zaslavsky, A.M. Short screening scales to monitor population prevalences and trends in non-specific psychological distress. Psychol. Med. 2002, 32, 959-976. [CrossRef]

40. Australian Institute of Health and Welfare. The Active Australia Survey; Australian Institute of Health and Welfare: Canberra, Australia, 2003.

41. Australian Government Department of Health. Australia's Physical Activity and Sedentary Behaviour Guidelines; Australian Government Department of Health Canberra: Canberra, Australia, 2014.

42. Babor, T.; Higgins-Biddle, J.; Saunders, J.; Monteiro, M. The Alcohol Use Disorders Identification Test; Department of Mental Health and Substance Dependence, WHO, Ed.; World Health Organization: Geneva, Switzerland, 2001.

43. Berman, A.H.; Bergman, H.; Palmstierna, T.; Schlyter, F. Evaluation of the drug use disorders identification test (dudit) in criminal justice and detoxification settings and in a swedish population sample. Eur. Addict Res. 2005, 11, 22-31. [CrossRef]

44. Sleep Health Foundation. Sleep Needs Across the Lifespan; Sleep Health Foundation: Blacktown, Australia, 2015.

45. World Health Organization. Obesity: Preventing and Managing the Global Epidemic. Report of a WHO Consultation; World Health Organization: Geneva, Switzerland, 2000.

46. Australian Government Department of Education and Training. Higher Education Statistics-2017 Student Data; Australian Government Department of Education and Training: Canberra, Australia, 2017.

47. Walther, J.; Aldrian, U.; Stuger, H.P.; Kiefer, I.; Ekmekcioglu, C. Nutrition, lifestyle factors, and mental health in adolescents and young adults living in austria. Int. J. Adolesc Med. Health 2014, 26, 377-386. [CrossRef]

48. Chu, J.J.; Khan, M.H.; Jahn, H.J.; Kraemer, A. Sense of coherence and associated factors among university students in china: Cross-sectional evidence. BMC Public Health 2016, 16, 336. [CrossRef]

49. Khanna, P.; Chattu, V.K.; Aeri, B.T. Nutritional aspects of depression in adolescents -A systematic review. Int. J. Prev. Med. 2019, 10, 42.

50. Molendijk, M.; Molero, P.; Ortuño Sánchez-Pedreño, F.; Van der Does, W.; Angel Martínez-González, M. Diet quality and depression risk: A systematic review and dose-response meta-analysis of prospective studies. J. Affect. Disord. 2018, 226, 346-354. [CrossRef]

51. Firth, J.; Marx, W.; Dash, S.; Carney, R.; Teasdale, S.B.; Solmi, M.; Stubbs, B.; Schuch, F.B.; Carvalho, A.F.; Jacka, F; et al. The effects of dietary improvement on symptoms of depression and anxiety: A meta-analysis of randomized controlled trials. Psychosom Med. 2019, 81, 265-280. [CrossRef] [PubMed]

52. Schultchen, D.; Reichenberger, J.; Mittl, T.; Weh, T.R.M.; Smyth, J.M.; Blechert, J.; Pollatos, O. Bidirectional relationship of stress and affect with physical activity and healthy eating. Br. J. Health Psychol. 2019, 24, 315-333. [CrossRef] [PubMed]

53. Sarris, J.; Logan, A.C.; Akbaraly, T.N.; Amminger, G.P.; Balanzá-Martínez, V.; Freeman, M.P.; Hibbeln, J.; Matsuoka, Y.; Mischoulon, D.; Mizoue, T.; et al. Nutritional medicine as mainstream in psychiatry. The Lancet Psychiatry 2015, 2, 271-274. [CrossRef]

54. Kwan, B.; Rickwood, D.J.; Telford, N.R. Development and validation of mylifetracker: A routine outcome measure for youth mental health. Psychol. Res. Behav. Manag. 2018, 11, 67-77. [CrossRef] [PubMed]

55. Rickwood, D.J.; Mazzer, K.R.; Telford, N.R.; Parker, A.G.; Tanti, C.J.; McGorry, P.D. Changes in psychological distress and psychosocial functioning in young people visiting headspace centres for mental health problems. Med. J. Aust. 2015, 202, 537-542. [CrossRef] [PubMed]

56. Lim, S.Y.; Kim, E.J.; Kim, A.; Lee, H.J.; Choi, H.J.; Yang, S.J. Nutritional factors affecting mental health. Clin. Nutr. Res. 2016, 5, 143-152. [CrossRef]

57. Chang, S.C.; Cassidy, A.; Willett, W.C.; Rimm, E.B.; O’Reilly, E.J.; Okereke, O.I. Dietary flavonoid intake and risk of incident depression in midlife and older women. Am. J. Clin Nutr. 2016, 104, 704-714. [CrossRef]

58. Godos, J.; Castellano, S.; Ray, S.; Grosso, G.; Galvano, F. Dietary polyphenol intake and depression: Results from the mediterranean healthy eating, lifestyle and aging (meal) study. Molecules 2018, 23, 999. [CrossRef] 
59. Spencer, S.J.; Korosi, A.; Layé, S.; Shukitt-Hale, B.; Barrientos, R.M. Food for thought: How nutrition impacts cognition and emotion. npj Sci. Food 2017, 1, 7. [CrossRef]

60. Knuppel, A.; Shipley, M.J.; Llewellyn, C.H.; Brunner, E.J. Sugar intake from sweet food and beverages, common mental disorder and depression: Prospective findings from the whitehall ii study. Sci. Rep. 2017, 7, 6287. [CrossRef]

61. Griffiths, S.; Hay, P.; Mitchison, D.; Mond, J.M.; McLean, S.A.; Rodgers, B.; Massey, R.; Paxton, S.J. Sex differences in the relationships between body dissatisfaction, quality of life and psychological distress. Aust. N. Z J. Public Health 2016, 40, 518-522. [CrossRef] [PubMed]

62. Griffiths, S.; Murray, S.B.; Bentley, C.; Gratwick-Sarll, K.; Harrison, C.; Mond, J.M. Sex differences in quality of life impairment associated with body dissatisfaction in adolescents. J. Adolesc Health 2017, 61, 77-82. [CrossRef] [PubMed]

63. Mond, J.; Mitchison, D.; Latner, J.; Hay, P.; Owen, C.; Rodgers, B. Quality of life impairment associated with body dissatisfaction in a general population sample of women. BMC Public Health 2013, 13, 920. [CrossRef] [PubMed]

64. The University of Newcastle. Annual Report 2015; The University of Newcastle: Newcastle, Australia, 2016.

65. Ludy, M.J.; Crum, A.P.; Young, C.A.; Morgan, A.L.; Tucker, R.M. First-year university students who self-select into health studies have more desirable health measures and behaviors at baseline but experience similar changes compared to non-self-selected students. Nutrients 2018, 10, 362. [CrossRef]

66. Australian Bureau of Statistics. National Health Survey: First Results, 2017-18. Available online: https://www.abs.gov.au/ausstats/abs@.nsf/Lookup/by\%20Subject/4364.0.55.001 \{\}2017-18 \{\}Main\% 20Features \{\} Fruit\%20and\%20vegetable\%20consumption \{\} 105 (accessed on 28 February 2019).

67. Australian Bureau of Statistics. Australian Health Survey: Nutrition First Results-Foods and Nutrients, 2011-12. Discretionary Foods. Available online: http://www.abs.gov.au/ausstats/abs@.nsf/Lookup/ by\%20Subject/4364.0.55.007 \{\}2011-12 \{\}Main\%20Features \{\}Discretionary\%20foods \{\}700 (accessed on 28 February 2019).

(C) 2019 by the authors. Licensee MDPI, Basel, Switzerland. This article is an open access article distributed under the terms and conditions of the Creative Commons Attribution (CC BY) license (http://creativecommons.org/licenses/by/4.0/). 